Middle East Journal of Science(MEJS)

\title{
A NEW APPROACH TO THE PRODUCTION OF LAMINATED COMPOSITES CONSISTING OF AL2O3 REINFORCED AND UNREINFORCED 7039 AL ALLOY SHEETS
}

Ŭgur $A v c i^{* 1}$

${ }^{1}$ Kahramanmaraş Sütçü İmam Üniversitesi, 46100, Malatya, Türkiye

*uavci@ksu.edu.tr

In this study, Al2O3 particles with an average size of $6 \mu \mathrm{m}$ were reinforced with $15 \%$ by weight of 7039 Al alloy matrix by Vortex method and metal matrix composite sheet was obtained. Reinforced 7039 Al alloy and unreinforced 7039 Al alloy sheet were placed in specially prepared mold after surface cleaning. The metal matrix composites placed in the furnace together with the mold were kept in the oven at $630{ }^{\circ} \mathrm{C}$ for 30 minutes until approximately $30 \%$ liquid, $70 \%$ solid consistency. Immediately after applying pressure of approximately $7 \mathrm{MPa}$ to the semi-solid composite material in the mold removed from the furnace, the mold was placed in the annealing furnace in the same manner and left at approximately $600{ }^{\circ} \mathrm{C}$ for approximately 4 hours. The new layered composite material formed by the joining of the plates cooled in the kiln mold to 500 oC temperature was removed from the mold and cooled in water. The microstructure and mechanical properties of the composite material were determined by optical microscope, micro hardness and tensile tests.

Key words: $7039 \mathrm{Al}$ alloy, Vortex process, MMC, Layer Composite 


\title{
AL2O3 TAKVIYYLII VE TAKVIYYESIZ 7039 AL ALAŞIMLI LEVHALARDAN OLUŞAN TABAKALI KOMPOZIT MALZEMENIN ÜRETIMIINDE YENİ BİR YAKLAŞIM
}

\begin{abstract}
Bu çalışmada, ortalama boyutu 6 um olan Al2O3 partikülleri Vorteks yöntemi ile 7039 Al alaşımı matrise ağırlıkça \%15 oranında takviye edilerek metal matrisli kompozit levha elde edilmiştir. Takviyeli 7039 Al alaşımı ile takviyesiz $7039 \mathrm{Al}$ alaşımı levha, yüzey temizleme işlemlerinden sonra özel olarak hazırlanmış kalıp içine yerleştirildi. Kalıp ile birlikte firın içerisine yerleştirilen metal matrisli kompozitler yaklaşık olarak \%30 sıvı, \%70 katı kıvama gelene kadar firın içerisinde 630 oC sicaklikta 30dk bekletildi. Fırından çıkarılan kalıp içerisinde yarı katı durumdaki kompozit malzemelere yaklaşık 7 MPa basınç uygulandıktan hemen sonra, kalıp aynı şekilde tavlama firını içerisine yerleştirildi ve 600 oC'de yaklaşılk olarak 4 saat bekletildi. Fırında kalıp içerisinde 500 oC sicakliğına kadar soğutulan levhaların birleşimi ile oluşan yeni tabakalı kompozit malzeme, kalıptan çıkartılarak suda soğutuldu. Soğuma sonrası kesiti alınan kompozit malzeme levhaya optik mikroskop, mikro sertlik ve çekme deneyleri yapılarak mikro yapı ve mekanik özellikleri incelenmiștir.
\end{abstract}

Anahtar Kelimeler: 7039Al alaşımı, Vorteks yöntemi, MMK, Tabakalı Kompozit

\section{Giriş}

Tabakalı kompozit malzemeler ve fonksiyonel derecelendirilmiş malzemeler kendine özgü özellikler içermesi açısından bileşimin derecelendirilmesi ile mikroskobik olarak homojen olmayan yüksek performansa sahip yapılardır[1]. Mikro yapılarındaki sürekli değişimler tabakalı ve fonksiyonel derecelenmiş kompozit malzemeleri diğer ticari kompozit malzemelerden ayırır[2]. Bu ileri teknoloji malzemesi yüksek 1sı ve korozyon dayanımına sahip olup, ultra 1sı derecelerine karşı koyabilme kabiliyetine sahip olmaktadır[3]. Yaygın olarak tabakalı kompozitler seramik-metal kompozitlerden elde edilir, seramik kısım iyi termal ve korozyon direncine sahip iken metalik kısım üstün dayanım ve kaynak kabiliyeti sağlar[4].

Al2O3 seramik malzeme yüksek sertliğe sahip olduğundan dolayı üstün aşınma direncine sahiptir. Böyle bir seramik yüksek 1sıl iletkenliğe sahip olmasının yanı sıra metallerle kıyaslandığında düşük 1sıl genleşmeye sahiptir. A12O3 aynı zamanda sıcak asitlere karşı yüksek korozyon direncine sahip bir malzemedir [5-6].

Matris olarak hafif alüminyum alaşımlarının kullanılması, yüksek özellikte dayanımlı malzemelerin birçok uygulaması için gerekmektedir. Hafif zırhlı araçlar bu uygulamanın bir örneğidir. 7039 alüminyum alaşımı, benzer yoğunluktaki alaşımlara ve aynı karakteristikteki yapılara göre daha yüksek 
dayanıma sahip olduğundan dolayı, matris malzemesi olarak kullanımı tercih edilmektedir[7,8]. Tablo 1'de genel itibariyle 7039 alüminyum alaşımının içeriği verilmektedir[9]. 7039, 1sıl işlem yapılabilen bir alüminyum alaşımıdır ve $\mathrm{Mg}(\mathrm{Zn}, \mathrm{Al}, \mathrm{Cu}) 2$ çökeltisinin çok iyi dağılımı sonucunda, alaşım dayanıklılığı arttırılmaktadır[10].

Tablo 1. 7039 Alüminyum Alaşımının İçeriği

\begin{tabular}{|c|c|c|c|c|c|c|c|c|}
\hline Mg & Zn & Mn & $\mathrm{Cr}$ & $\mathbf{S i}$ & $\mathbf{F e}$ & $\mathrm{Cu}$ & $\mathbf{T i}$ & Al \\
\hline $2.3-3.3$ & $3.5-4.5$ & $\begin{array}{l}0.10- \\
0.40\end{array}$ & $\begin{array}{l}0.15- \\
0.25\end{array}$ & $0.30 \max$ & $0.40 \max$ & $0.10 \max$ & $0.10 \max$ & Kalan \\
\hline
\end{tabular}

Yukarıda açıklanan özellikler göz önüne alındığında, A12O3 takviye edilmiş 7039 alüminyum alaşımlı bir kompozit malzemenin üretilmesinin avantajları tahmin edilebilmektedir. $\mathrm{Bu}$ tür bir üretimin gerçekleştirilebilmesi için toz metalurjisi ve sıkıştırma döküm gibi teknikler geliştirilmiştir. $\mathrm{Bu}$ tekniklerle birlikte Vorteks yöntemi de ticari açıdan uygulanabilir bir metot olarak kabul edilmiştir. Üretim şeklinin sadeliği, esnekliği ve geniş hacimli üretimler için uygulanabilirliği bu yöntemi daha avantajlı kılmaktadır[11]. Takviye malzemesi ile matris alaşımı arasındaki kimyasal reaksiyon ile ilgili zorluklar ve takviye partiküllerinin üniform olarak dağılımının sağlanamaması, bu yöntemin dezavantajlarını oluşturmaktadır[12].

\section{Yöntem}

Bu çalışmada 650 gr Al 7039 alaşımı grafit pota içerisine yerleştirildi ve Şekil 1'de verilen firında 750 oC'de ergitilerek ağırlıkça \% 15 oranında ortalama boyutu $6 \mu \mathrm{m}$ olan $\mathrm{Al} 2 \mathrm{O} 3$ partikülleri takviye edilmiştir. Eriyik haldeki matris alaşımının oksitlenmesini önlemek amacı ile firın atmosferine \%99,99 saflıkta argon gazı 15 lt/dak hızda gönderilmiştir. Al2O3 partiküllerinin matris tarafindan 1slatılabilirliğini artırmak ve aglomerasyonlarını (topaklaşma) önlemek amacıyla bu partiküller $800 \mathrm{oC}$ 'de yaklaşı 1 saat ön 1sıtma işlemine tabi tutulmuşlardır. Ön 1sıtma işlemine tabi tutulan partiküller eriyik matris alaşımı içine kademeli olarak ilave edildikten sonra grafit karıştırıcılar vasıtasıyla 1050 d/dak dönme hızında karıştırılmıştır. Karıştırma işlemi sonrasında 450oC'de ön 1sıtma işlemi yapılmış 120x120x15 mm ebadındaki metal kalıba eriyik karışım dökülmüş ve katılaşma tamamlanana kadar porozitelerin azalması amacı ile metal kalıba $5 \mathrm{MPa}$ basınç uygulanmıştır. 


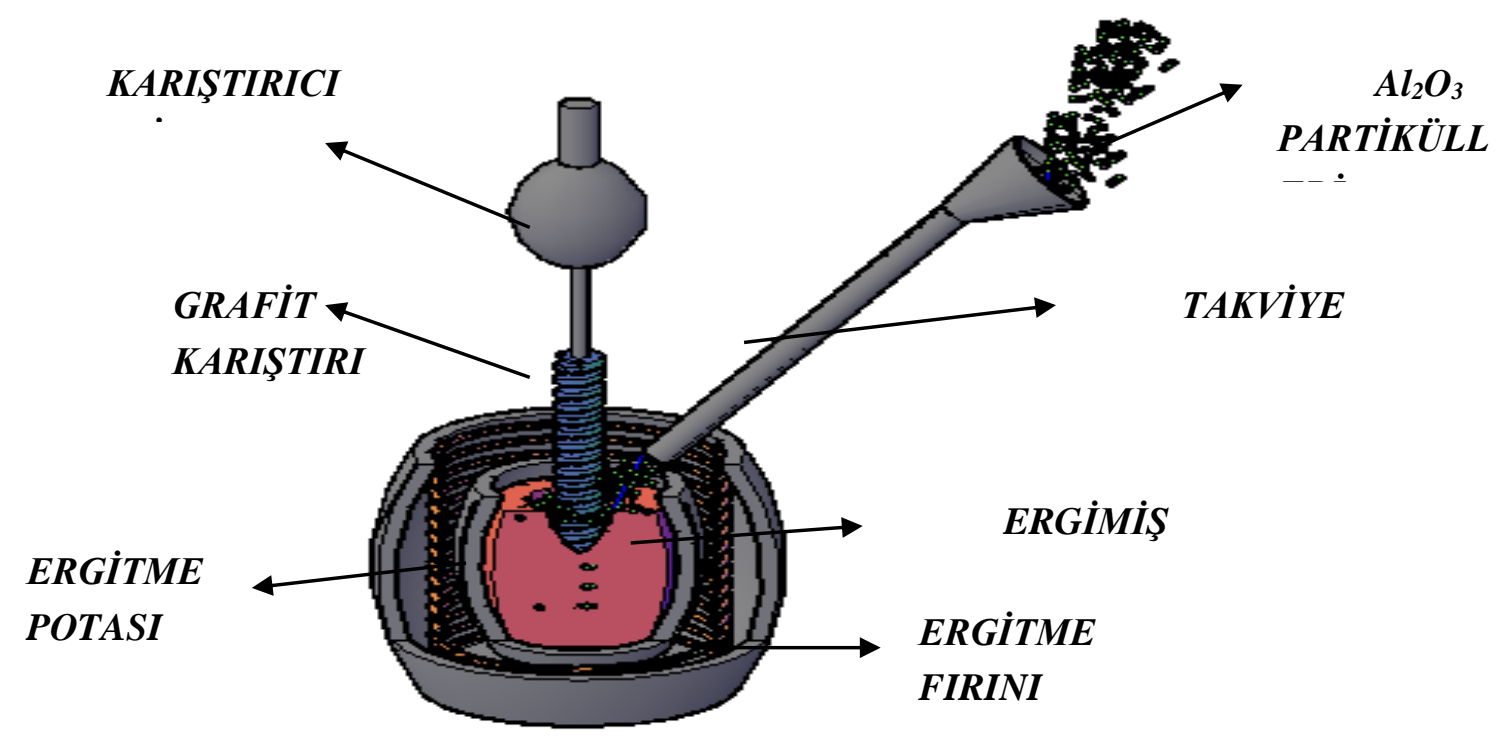

Şekil 1. Vorteks Yöntemi Bileşenlerinin Kesit Görünümü

Al2O3 partikülleri takviye edilen metal matrisli kompozit levha ile takviyesiz 7039 Al alaşımlı levha yüzey temizleme işlemlerinden sonra Şekil 2'de gösterildiği gibi özel olarak hazırlanmış kalıp içine yerleştirildi. Kalıp ile birlikte firın içerisine yerleştirilen levhalar yaklaşık olarak \%30 sıvı, \%70 katı kıvama gelene kadar fırın içerisinde 630 oC sıcaklıkta 30dk bekletildi. Fırından çıkarılan kalıp içerisinde yarı katı durumdaki kompozit malzemelere yaklaşı 7 MPa basınç uygulandıktan hemen sonra, kalıp aynı şekilde tavlama firını içerisine yerleştirildi ve 600 oC'de yaklaşı olarak 4 saat bekletildi. Fırında kalıp içerisinde 500 oC sıcaklığına kadar soğutulan yeni tabakalı kompozit malzeme, kalıptan çıkartılarak suda soğutuldu. 


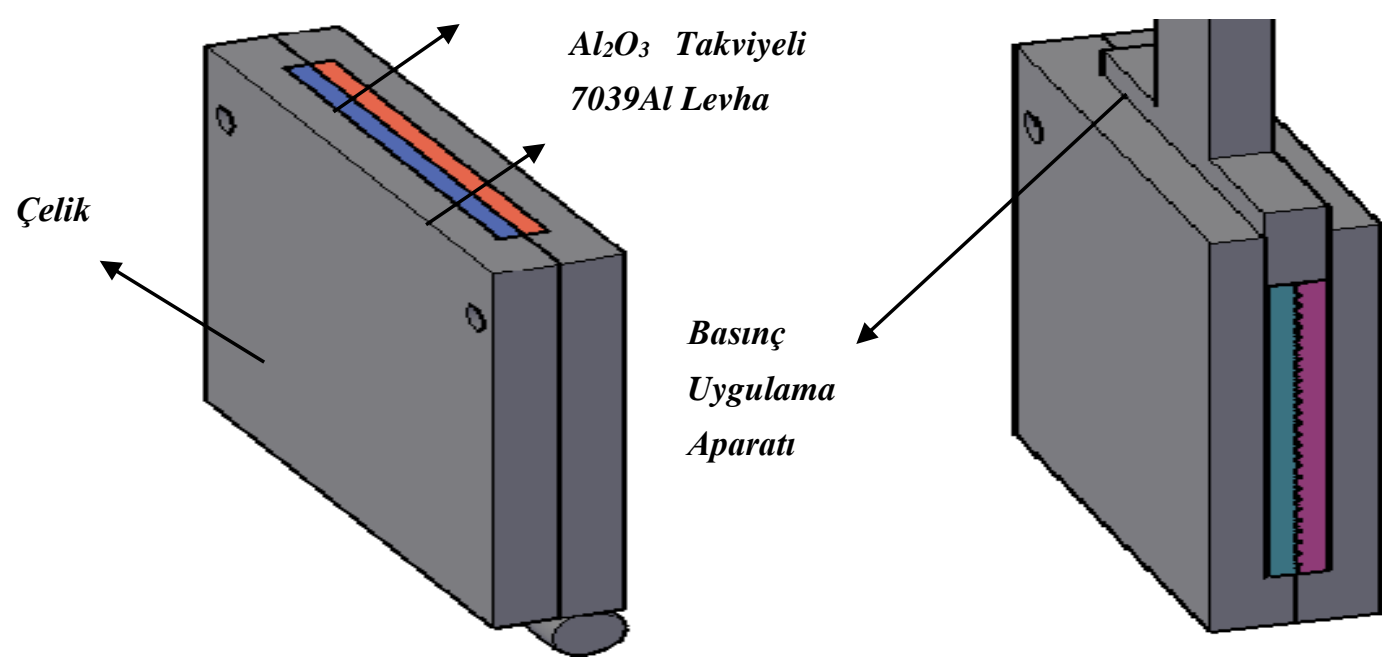

\section{Şekil 2. Takviyeli Ve Takviyesiz 7039 Al Levhaların Kalıp İçerisine Yerleşimi Ve Isıtılan Levhalara Basınç Uygulaması}

Tabakalı kompozit malzemeden alınan numuneler zımparalama ve parlatma işleminden sonra Keller kimyasalında (1 ml HF, 1,5 ml HCl, 2,5ml HNO3, $95 \mathrm{ml} \mathrm{H2O}$ ) dağlanmıştır. LEICA DM4000M cihazda optik mikroskop ve Shimadzu GMV-20 cihazında 100 gr yük kullanılarak mikro sertlik ölçümleri yapılmıştır. Her bir bölge için üç adet sertlik ölçümü yapılmıştır. Çekme deney numuneleri ASTM E 8 M-04 standardının belirttiği ölçülerde malzeme yapısını değiştirmeden tel erozyon tezgahında istenilen ölçülere getirilmiştir. Çekme deneyleri ZwickZ100 marka çekme-basma cihazında yapılmıştır.

Vitaminlerin analizinde Agilent 1100 Serisi yüksek performanslı sıvı kromatoğrafi (HPLC) cihazı kullanılmıştır. Dedektör olarak UV-DAD kullanılmıştır. Ters fazlı ACE 5 C-18-A11608 (250x4.6 mm, ID) ayırma kolonu kullanılmıştır.

Vitaminlerin HPLC analizinde ise Eluent A (\%3 Asetik asit:\%97su) ve eluent B (\%3 Asetik asit:\%25 Asetonitril:\%72 su) şeklindeki çözgen karışımı kullanılmıştır. Bu gradient profili Tablo 1. de verilmiştir.

\section{Bulgular}

\subsection{Mikro Yapı İncelemeleri}

Resim 1'de \%15 ağırlık oranında Al2O3 takviye edilmiş 7039 Al matrisli kompozit malzeme ile takviyesiz 7039 Al malzemeden oluşan tabakalı kompozit malzemenin genel mikro yapısı gösterilmektedir. Resmin alt kısmında $\mathrm{A} 12 \mathrm{O} 3$ partiküllerinden oluşmuş olan levha, üst kısmında ise takviyesiz levha ve orta kısımda net bir birleşim görülmektedir. Uygulanan basıncın etkisiyle malzemelerin birleşim bölgesinde dalga şeklinde bir dağılım oluşmaktadır. Resim 2a'da A12O3 partiküllerinin dağılımı görülmekte olup, partikül dağılımında küçük çapta aglomera oluşumu olmasına rağmen, genel itibariyle bakıldığında düzgün bir dağılım ortaya konulmuştur. Vorteks yöntemiyle partikül takviyeli kompozit üretiminde, takviye elemanının ilave hızı, karıştırma süresi, karıştırıcı şekli veya karıştırıcı hızındaki en ufak tutarsızlık partikül topaklanmasına neden olmaktadır[13]. 

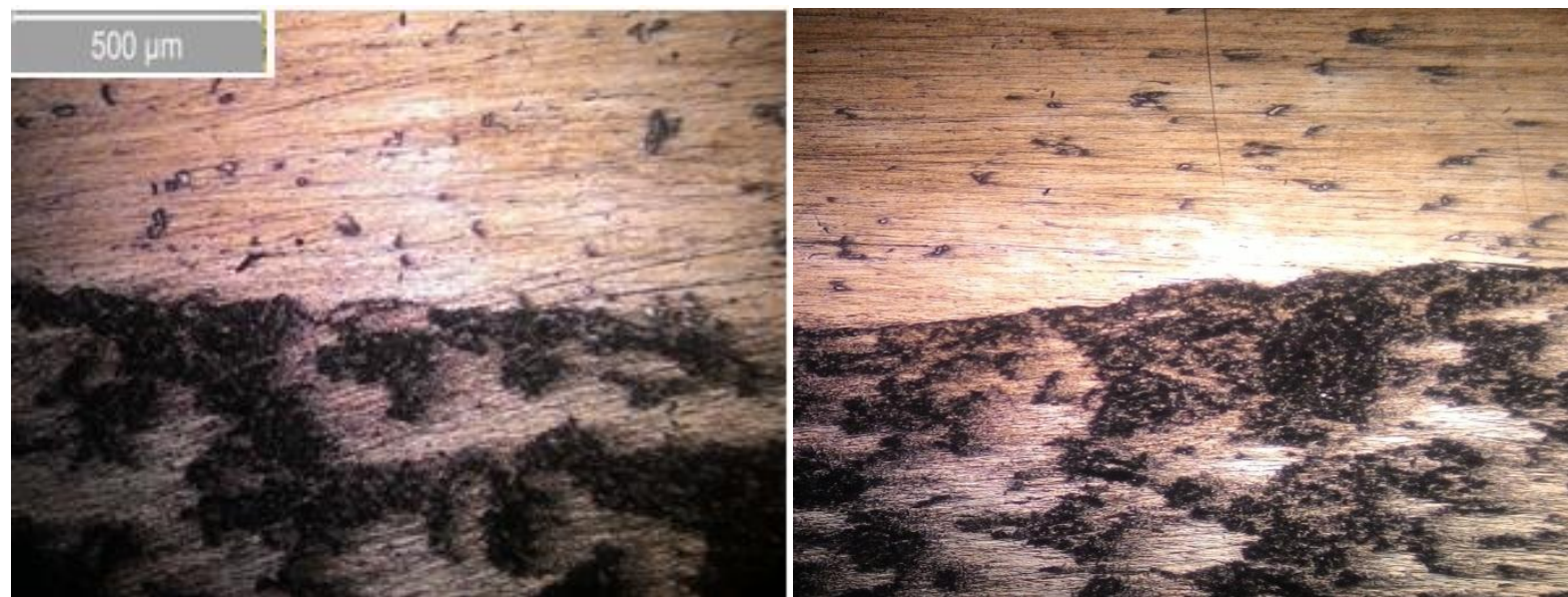

Resim 1. \%15 Ağırlık Oranında Al2O3 Takviye Edilmiş 7039 Al Matrisli Kompozit Malzeme İle Takviyesiz 7039 Al Malzemeden Oluşan Tabakalı Kompozit Malzemenin Genel Mikro Yapısı

Resim 2b'de 7039 Al alaşımının mikro yapısı verilmiştir. Uygulanan sıcaklık ve basıncın etkisi ile çamur kıvamına gelen numuneler kısmi ergime sırasında mikro yapısal değişime uğrarlar. Al alaşımlarında düşük enerjili tane sınırlarına sahip olan komşu taneler birleşerek tane irileşmesine yol açarlar[14]. Üretim sırasında uygulanan basınç ve sıcaklık dışında kompozit numuneye herhangi bir deformasyon ya da $1 s ı 1$ işlem uygulanmadığından iri taneli yapı Resim 2b’ de görülmektedir.

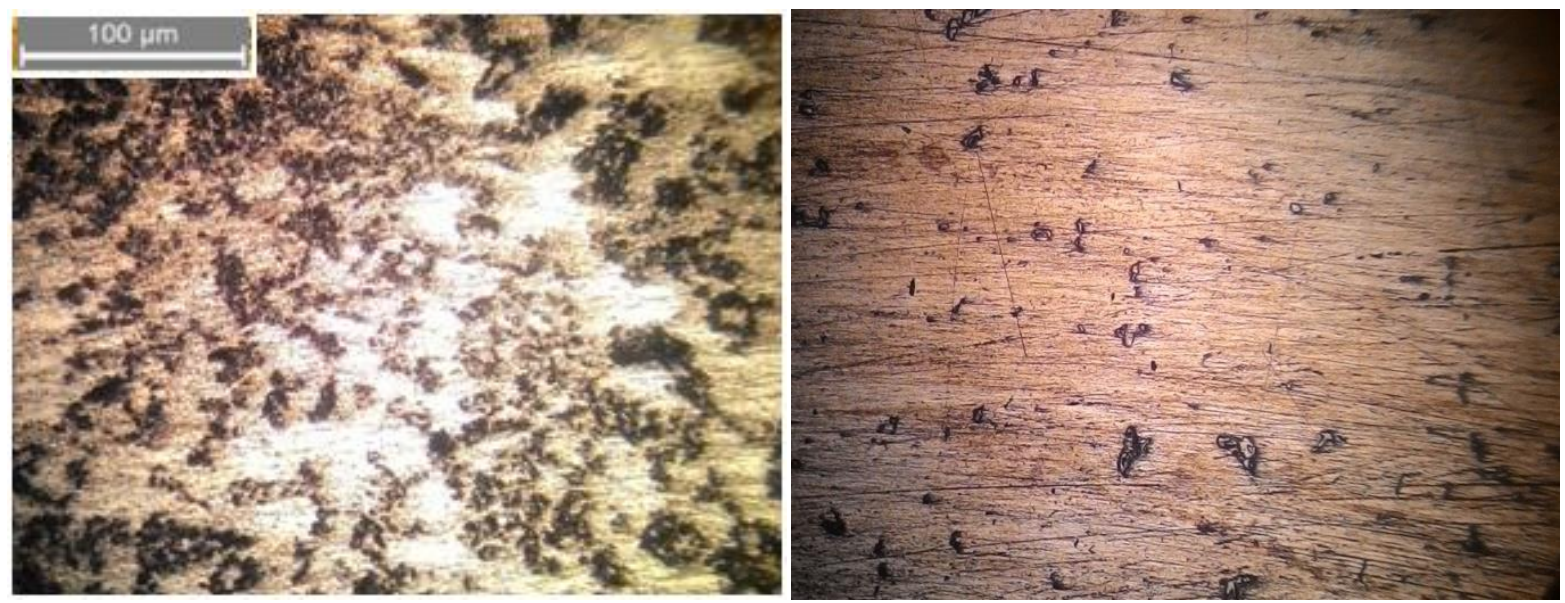

Resim 2 a. Al2O3 Takviye Partiküllerinin Dağılımı, b. 7039 Al Malzemenin Genel Mikro Yapısı

\subsection{Mikro Sertlik Sonuçları}

Üretimi tamamlanmış olan tabakalı kompozit malzemenin sertlik ölçümü için belirlenen bölgeleri ve aldığımız sertlik sonuçları ortalaması grafiksel olarak Resim 4'de gösterilmektedir. Matris malzemeyi oluşturan 1. bölgeden aldığımız sertlik sonuçları ortalaması yaklaşık olarak $112 \mathrm{HV}$ olarak ölçülmüştür. Partiküller arasında bulunan matris malzemeyi oluşturan 2. Bölgeden aldığımız sertlik sonuçları ortalaması yaklaşık olarak 123 HV olarak ölçülmüştür. Ana matris malzeme ile Al2O3 partikülleri ara bölgesinde bulunan matris malzemesi arasında oluşan bu sertlik değeri farkının, partiküller etrafında toplanan dislokasyon yoğunluğuna bağlamak mümkündür. Bu yüksek dislokasyon yoğunluğu A12O3 ve $\mathrm{Al}$ arasındaki ısıl genleşme katsayısındaki yüksek farktan meydana geldiği düşünülmektedir. Ölçüm 
cihazının bir ucunun takviye partikülüne bir ucunun ise matris malzemeye temasıyla oluşturulmuş olan 3. bölgeden aldığımız sertlik sonuçları ortalaması yaklaşık olarak 140 HV olarak ölçülmüştür. Sadece A12O3 partikülünün oluşturduğu 4. bölgeden aldığımız sertlik sonuçları ortalaması yaklaşık olarak 221 HV olarak ölçülmüştür.

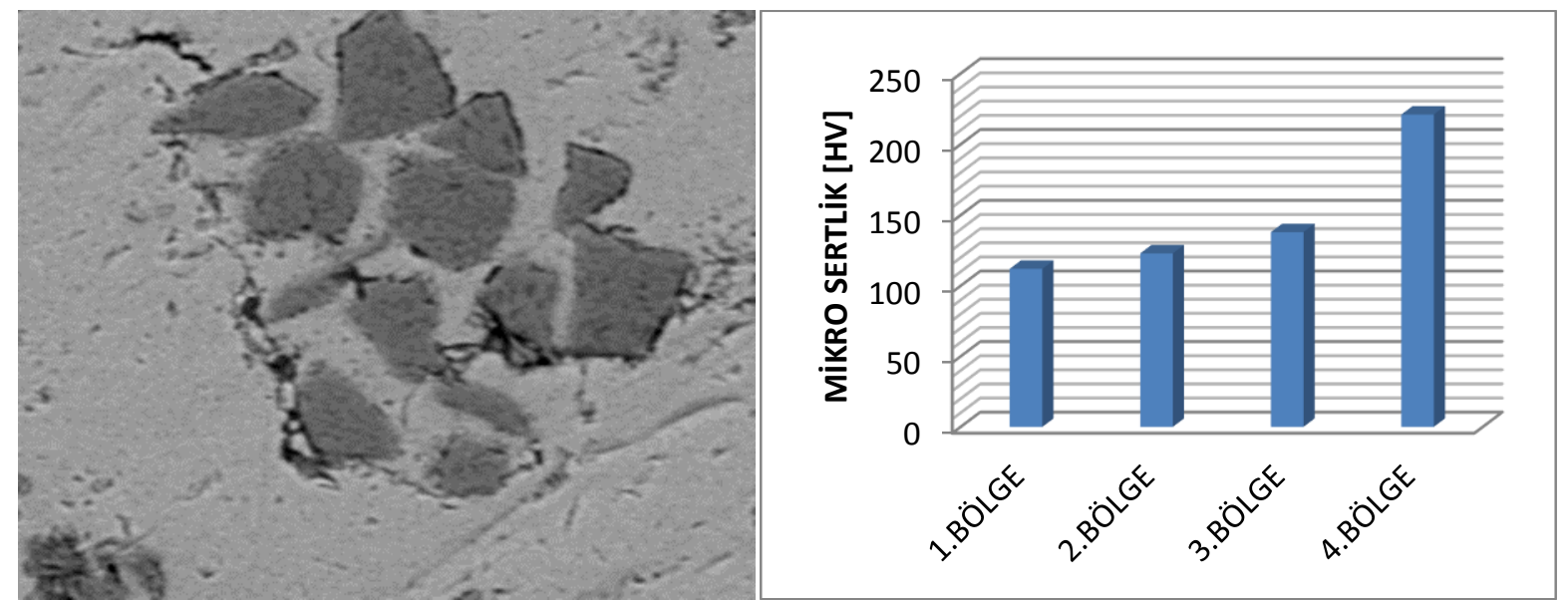

Resim 4. Sertlik Ölçüm Bölgeleri Ve Alınan Sertlik Sonuçları Ortalamasının Grafiksel Gösterimi

Mikro sertlik sonuçlarının geneline bakıldığında A12O3 partiküllerinin dağılımı ile birlikte hem partiküller hem de partikül ara bölgeleri vasıtasıyla, sertlikte partikül dağılımı boyunca bir şekil sertlik değeri $\mathrm{A} 12 \mathrm{O} 3$ partiküllü takviyeli kısımda yüksek olmakla birlikte, takviyesiz tabakalı kısımda ise düşük bir değerde bulunmaktadır.

\section{3. Çekme Deney Sonuçları}

Yeni bir yaklaşımla üretilmiş olan tabakalı kompozit malzeme, Şekil 3'de verilen ölçülerde kesilerek çekme testi için hazır hale getirilmiştir. Çekme deney sonuçları Tablo 2'de verilmekle birlikte, oluşan deney grafiği Şekil 4'de gösterilmektedir.

Tablo 2. Üretilen Tabakalı Kompozitin Çekme Deney Sonuçları

\begin{tabular}{|c|c|c|c|c|}
\hline & $\begin{array}{c}\text { Tabakalı Kompozit } \\
\text { Özelliği }\end{array}$ & Çekme Dayanımı & $\begin{array}{l}\text { Uzama \% } \\
\varepsilon\end{array}$ & Kopma Dayanımı \\
\hline $\begin{array}{l}\% 15 \\
\text { Takvi }\end{array}$ & $\begin{array}{c}\mathrm{Al}_{2} \mathrm{O}_{3} \text { Takviyeli ve } \\
\text { yesiz } 7039 \mathrm{Al}\end{array}$ & 109,138 & 0,49 & 104,021 \\
\hline
\end{tabular}




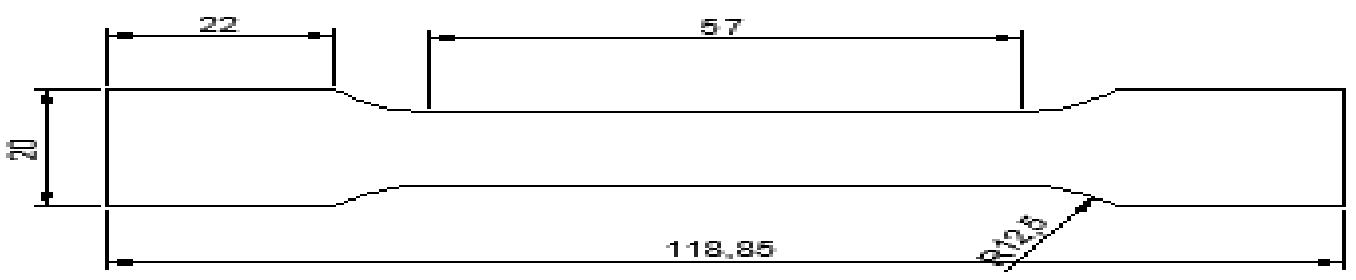

Şekil 3. Hazırlanan Çekme Numunesi Ölçüleri

Elde edilen çekme deney sonuçlarına göre üretimi tamamlanan tabakalı kompozit malzemenin çekme dayanımı $7039 \mathrm{Al}$ alaşımına kıyasla düşük çıkmıştır. Resim 5'te verilen çekme testi sonucunda oluşan kırılma durumu malzemenin aynı zamanda, aynı bölgeden koptuğunu göstermekle birlikte, takviyesiz alaşım malzemesi ile takviyeli kompozit malzeme arasında kuvvet aktarımının gerçekleştiğini göstermektedir. \%15 Al2O3 partikül takviyeli 7039 Al kompozit malzemenin çekme dayanımının düşük olması nedeniyle, takviyesiz 7039 Al alaşımlı malzemenin test sırasında ideal bir kuvvet paylaşımı gerçekleştirmiştir olduğu söylenebilir.

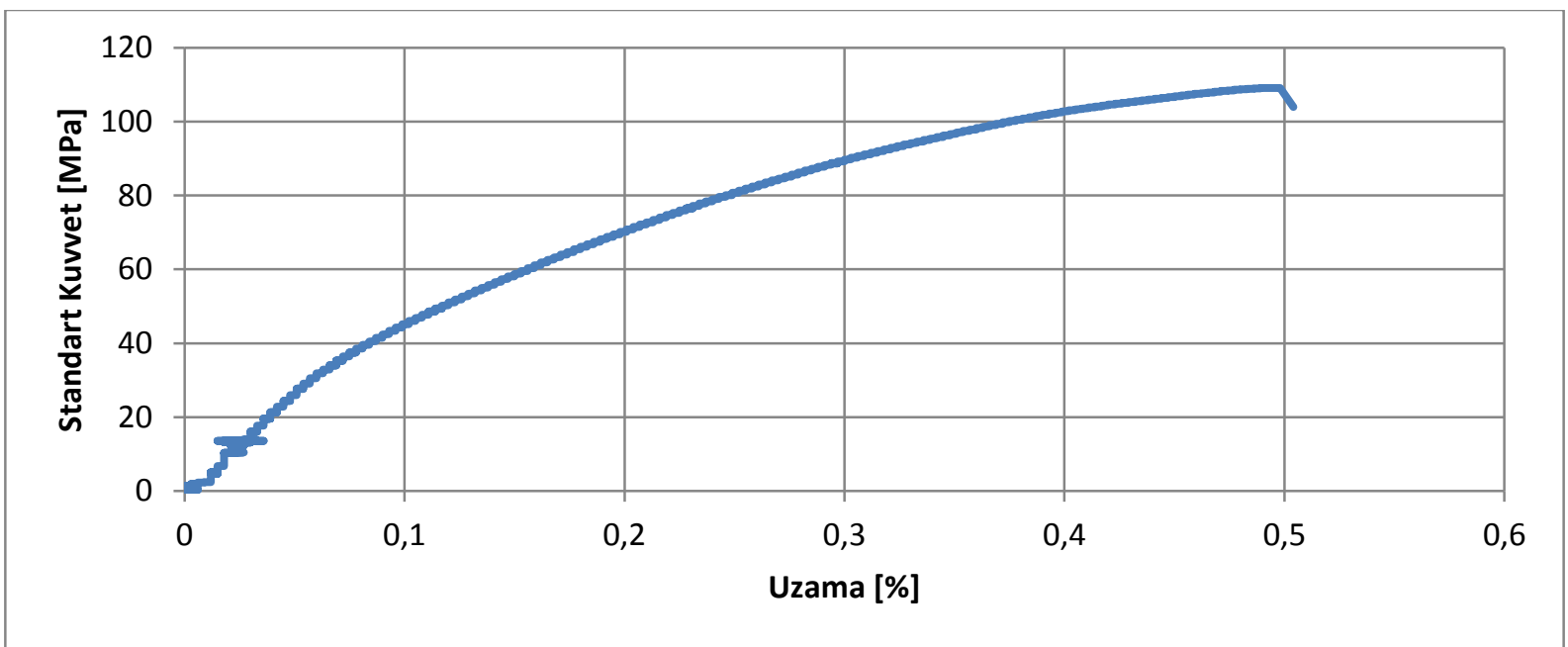

\section{Şekil 4. Çekme Deneyi Grafik Gösterimi}
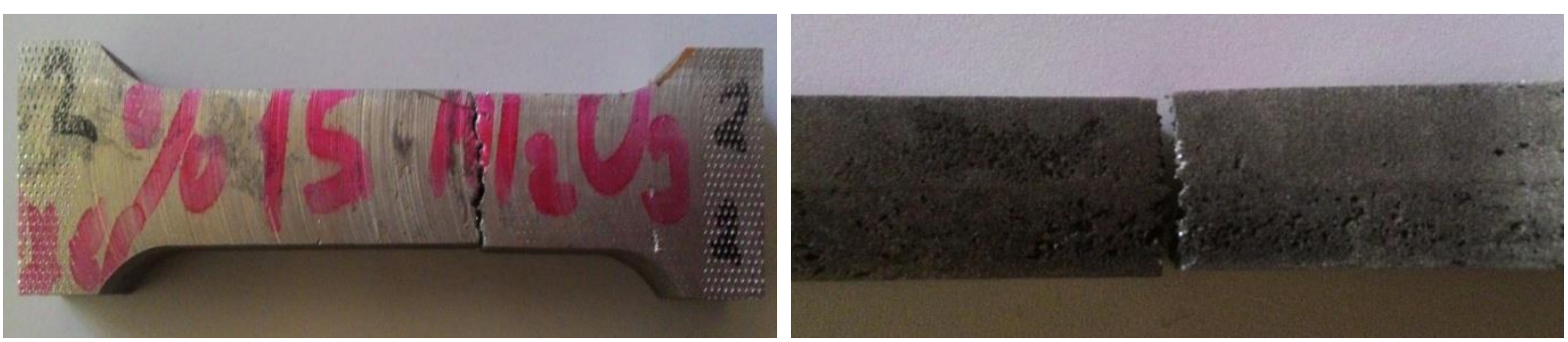

Resim 5. Tabakalı Kompozit Malzemenin Çekme Deneyi Sonrası Kırılma Durumu

\section{Sonuçlar}

Bu çalışmada, matris olarak 7039 Al malzemesine takviye elemanı olarak $6 \mu \mathrm{m}$ boyutlarında Al2O3 partikülleri Vorteks yöntemi kullanılarak ağırlıkça \% 15 oranında takviye edilmiş olup, sonrasında bu malzeme takviyesiz $7039 \mathrm{Al}$ alaşımlı malzeme ile yeni bir üretim tekniği ile tabakalı kompozit malzeme haline getirilmiştir. 
1-Üretilen tabakalı kompozit malzemenin mikro yapı incelemeleri $\mathrm{Al} 2 \mathrm{O} 3$ takviye partiküllerinin 7039 matris malzemesi içerisine dağılımının gerçekleştiğini ve metal matrisli kompozit ile alaşımlı Al malzemenin birleşiminde herhangi bir problemin olmadığ gözlemlenmektedir. Birleşim bölgesinde oluşan dalga modeli, tabakalı kompozit malzeme üretiminde uygulanan basınç sonucu oluşmuştur.

2- Tabakalı kompozit malzemenin sertlik ölçüm sonuçları matris malzemede ortalama $112 \mathrm{HV}$, Al2O3 partikülleri arasında bulunan matris malzemeden alınan sertlik sonucu yaklaşık olarak $123 \mathrm{HV}$, ölçüm cihazının bir ucunun matris malzemeye diğer ucunun partikül malzemeye teması ile ölçülen sertlik değerinin yaklaşı olarak $140 \mathrm{HV}$ ve son olarak partikülden alınan sertlik değeri yaklaşık olarak 221 HV olarak ölçülmüştür. Ölçüm değerleri üretilen tabakalı malzemenin bir yüzeyindeki sertlik değeri ile diğer yüzeyindeki sertlik değeri arasında yüksek bir farkın olduğunu ortaya koymaktadır.

3- Üretimi tamamlanan tabakalı kompozit levhadan alınan çekme numunesi, test sonunda ideal bir kırılma sergilemiştir. Ortaya konulan bu yöntemle birleştirilmiş olan iki levha, bir bütün malzemenin kırılma özelliğini göstererek üretim tekniğindeki yaklaşımın doğruluğunu ileri sürmektedir. $7039 \mathrm{Al}$ alaşımlı levhanın çekme dayanımı ile kıyaslandığında, tabakalı kompozit levhanın çekme dayanımının düşük olduğu ortaya çıkmaktadır. Bunun takviyesiz malzeme ve takviyeli malzeme arasındaki kuvvet aktarımından kaynaklandığı düşünülmektedir.

\section{Kaynakça}

[1] Koizumi, M. (1997). FGM activities in Japan. Composites, B 28, 1-4.

[2] Wang, S.S. (1983). Fracture mechanics for delamination problems in composite materials. J. Compos. Mater. 17 (3), 210-223.

[3] Niino, M., Hirai, T.,\& R. Watanable. (1987). The functionally gradient materials. J.Jpn.Soc. Compos. Mater. 13, 257-264.

[4] Shanmugavel P., Bhaskar, G.B., Chandrasekaran, M., Mani, P.S., \& S.P. Srinivasan. (2012). An overview of fracture analysis in functionally graded materials, Eur.J.Sci. Res. 68 (3), 412-439.

[5] Jha, D.K., Kant, T., \& Singh, R.K. (2013). Critical review of recent research on functionally graded plates, Compos. Struct. 96, 833-849.

[6] North, B. (1987). Int. J. High Tech. Ceramics, 3, 113-127.

[7] Adams, J. H., Anschuetz, B., \& Whitfield, G. (1991). Ceramic Cutting Tools. In Engineered Materials Handbook, Vol. 4, Ceramics and Glasses, ASM International, Metals Park, OH, p. 966.

[8] Montgomery, J.S., \& Chin, E.S. (2004). The AMPTİAC Quarterly,8 (4), 16.

[9] Perez-Bergquist, Sara J., Gray III, G.T. (Rusty)., Cerreta, Ellen K., Trujillo, Carl P., \& PerezBergquist, Alex. (2011). The dynamic and quasi-static mechanical response of three aluminum armor alloys: 5059, 5083 and 7039. Materials Science and Engineering. A 528, 8733-8741.

[10] Trotten, G.E., \& MacKenzie, D.S. (2003). Al-Zn-Mg alloys, in: Handbook of Aluminum, Marcel DekkerInc., NY, 185-194. 
[11] Abdizadeh, H., Baharvandi, H.R., \& Shirvani Moghaddam, K. (2008). Effect of B 4 C, TiB 2 and $\mathrm{ZrSiO} 4$ ceramic particles on mechanical properties of aluminium matrix composites: Experimental investigation and predictive modelling. Mater. Sci. Eng. A 498, 53-58.

[12] Onat, A., Akbulut, H., \& Y1lmaz, F. (2007). Journal of Alloys and Compound. 436 375-382.

[13] Chen, R., \& Zhang, G. (1993). Casting defects and properties of cast A356 aluminium alloy reinforced with $\mathrm{SiC}$ particles. Composites Science and Technology. Vol. 47, pp. 51-56.

[14] Bolourı, A., Shahmırı, M., \& Cheshmeh, E. N. H. (2010). Microstructural evolution during semisolid state strain induced melt activation process of aluminum 7075 alloy. Trans. Nonferrous Met. Soc. China 20, 1663-1671. 